\title{
Modeling Physical-Social Resilience in District 1 of Tehran
}

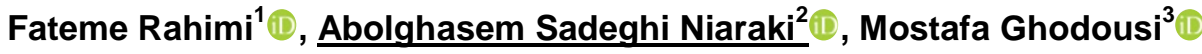

Date of submission: 23 Sep. 2019 Date of acceptance: 21 May. 2020

\begin{abstract}
INTRODUCTION: Today, the expansion of urbanization has located cities and residential areas in places exposed to various types of hazards. Natural hazards are characterized by low predictability and can cause numerous human and financial losses to urban settlements. Making cities resilient is one of the United Nations International strategies for disaster mitigation. With this background in mind, the present study aimed to prepare a physical-social resilience map of the study area.

METHODS: This descriptive-analytical identified the criteria and indicators of physical and social dimensions after the revision of experimental and theoretical texts. After the identification of indicators, the map of the resilience or non-resilience of the indicators was prepared in binary form. Finally, two methods of Boolean and indicator overlap were used to combine the layers. In the current research, the Fuzzy Analytical Hierarchy Process-Technique (FAHP) was used for weighting the map of the studied layers.

FINDINGS: Based on the result of the Boolean model map, more than half of the total district will be non-resilient. Nonetheless, according to the result of the indicator overlap method, $7.68 \%, 24.71 \%$, and $67.61 \%$ of the total district has low, average, and high resilience, respectively.

CONCLUSION: According to the resilience map obtained in the study area, it can be stated that resilience in these areas is not favorable. Moreover, Darband region and its surrounding streets are not in good condition. Therefore, management programs should be implemented in lowresilient areas before the onset of disasters.
\end{abstract}

Original Article

Keywords: Boolean Method; Indicator Overlap Method; Multiple-Criteria Decision-Making; Resilience; Spatial Information System.

How to cite this article: Rahimi F, Sadeghi Niaraki A, Ghodousi M. Modeling Physical-Social Resilience in District 1 of Tehran. Sci J Rescue Relief 2020; 12(1): 46-56.

\section{Introduction}

$\mathrm{T}$ loday, cities and neighborhoods are built in places exposed to a variety of natural and man-made disasters. Natural hazardinduced disasters can cause a great deal of financial and human losses annually in developing countries (1). Until the 1980 s, there was a confrontational approach to hazards; nonetheless, from the 1980s onwards, especially in the 1990s, this approach underwent a significant global shift to enhancing

disaster resilience (2).
Although some predictive tools are effective in mitigating the effects of crises, future hazards cannot be predicted on the basis of evidence. Therefore, it is necessary to recognize the resilience of the local community to prevent vulnerabilities (3). In recent years, the activities of most organizations and institutions active in the field of crisis management have focused on the achievement of a more resilient society.

The identification of how indicators of resilience affect and are affected by each other, as well as the key and strategic factors of society,

1-MA student, Spatial Information Systems Engineering, Khajeh Nasir al-Din Toos University of Technology

2- PhD, Faculty of Surveying Engineering, Khajeh Nasir al-Din Toosi University of Technology

3-PhD Student, Spatial Information Systems, Faculty of Surveying Engineering, Khajeh Nasir al-Din Toosi University

Correspondence to: Abolghasem Sadeghi Niaraki, Email: a.sadeghi@kntu.ac.ir 
will be of great help to society in planning for resilience (4). Its results can also be used to increase the resilience, planning, and policies of authorities regarding natural disaster management (5). The term resilience was first coined in 2005 at the Hyogo Conference on disaster management (6). The word resilience is derived from the Latin word "resilio" meaning "to bounce back suddenly" (7).

Resilience can be considered an accepted term in crisis management, even if it is derived from ecology, psychology, physics, and other sciences (8). The concept of resilience was introduced by Halig in 1973 as a descriptive term and has since been used in various scientific fields, such as ecology, economics, politics, and psychology (9). In a general sense, resilience is the ability of an atrisk system, element, or community to absorb turmoil in such a way that it remains the same as before, and increases its learning and organizing capacity (10).

Owing to its geographical and geological location, Iran is one of the top ten countries facing natural and catastrophic disasters (11). Most Iranian cities are located in high-risk areas. Among these cities, Tehran is in unfavorable conditions due to the high share of the urban population, aged buildings, and the existence of three active faults. The aforementioned issues and the critical importance of urban resilience highlight the necessity of evaluating and modeling urban resilience against hazards, especially in Tehran.

Today, due to the high applicability of resilience in various fields and the importance societies attach to the word resilience, the evaluation and measurement of this concept is a prerequisite for its practical and theoretical understanding (12). In recent years, numerous studies have been conducted on the assessment of urban resilience. Resilience is a multifaceted approach with four dimensions: social, economic, physical, and institutional.

The indicators of resilience vary across different study populations; therefore, special attention should be devoted to national studies in the selection of indicators and model presentation. In the following, a number of national studies have been investigated according to the dimensions of resilience. Some studies have merely focused on the institutional (managerial) dimension.
Badri et al. (2013) studied the role of local management in spatial resilience against natural disasters with an emphasis on floods. In the mentioned research, the managerial and institutional dimension was emphasized as a key dimension, and the required information was collected through the development of a questionnaire (8). Other studies have targeted the economic dimension. Bahrami et al. (2017) evaluated social and economic resilience in order to deal with the effects of disasters in urban neighborhoods of Sanandaj.

In the aforementioned research, the network analysis method was used to determine the importance of indicators (13). Other studies targeted the physical dimension. Rezaei et al. (2015) assessed and evaluated the resilience of urban neighborhoods in Tehran against earthquakes considering such indicators as ground features, structural strength, incompatible land uses, availability, density, and open spaces.

In the referred research, the required information was collected using the field method and questionnaire. Thereafter, the initial weighted decision matrix was prepared using the simple sum method, and the resilience status of the studied neighborhoods was calculated by the ELECTRE method. The results of the discussed research indicated that the studied neighborhoods were at different levels in terms of physical resilience (5).

Heidari Soureshjani et al. (2017) assessed and evaluated the physical resilience of the worn-out tissue of Bushehr against earthquakes with such indicators as building quality (construction quality and strength, resistance to earthquake), open space (map of evacuation routes, temporary accommodation, and shelter), access (access to police stations and main road network, awareness of open spaces, and access to public open spaces), and resistance (telecommunications, as well as the resistance of electrical installations and water pipes).

In the mentioned research, a questionnaire was used for data collection, and information processing was performed using structural equation modeling (14). Maleki et al. (2017) evaluated the physical resilience of Ilam using the Complex Proportional Assessment (COPRAS) COPRAS method. The indicators of the aforementioned research included the type of materials, building quality, land use, area of plots 
(square meters), access to the road and transport network (meters), and population density (15).

Zanganeh Shahraki et al. (2017) evaluated and analyzed the physical resilience of Tehran's 12th district using the Fuzzy Analytical Network Process (FANP )(16). Moreover, some other studies targeted the social component. Rousta et al. (2015) assessed social resilience according to such indicators as social capital (public trust, institutional trust, formal participation, informal participation, and awareness) and spatial affiliation. The obtained data were analyzed using the one-sample t-test and one-way analysis of variance (17).

Dalakeh et al. (2017) assessed social resilience in urban areas of Isfahan using the Topsis technique. The referred study used such indicators as justice in education, age, access to transportation, communication capacity, special needs, health coverage, language skills, social harm, sociability, family support, culture, and spatial affiliation have been used (18).

In general, it can be acknowledged that in the majority of mentioned studies, resilience has been evaluated using subjective approaches and less attention has been paid to objective approaches. In the objective method, secondary data (population density calculation) are used; nonetheless, in the subjective approach, the opinions of individuals and experts are used directly. One of the advantages of objective assessment is the use of publicly available data (secondary data).

Moreover, in most articles and studies, the network analysis method and fuzzy hierarchical analysis have been used for weighting and calculation of resilience. Therefore, in the present study, the fuzzy hierarchical method was used for weighing the information layers. In addition, just a few studies used Boolean and index overlap methods to combine research criteria to achieve the goal of resilience modeling.

The achievement of definite results is one of the reasons for using the Boolean method (the non-resilient region is definitely more nonresilient than other regions). The fuzzy hierarchical method allows decision-makers to express rough and flexible weights with fuzzy numbers.

Furthermore, most studies targeted physical or social resilience, and there is a paucity of studies on physical-social resilience.

As a matter of fact, the current study aimed to identify the indicators and factors affecting the physical-social resilience of the city to evaluate and model the physical-social resilience of District 1 of Tehran presenting two methods of Boolean and indicator overlap. In this article, the physical and social dimensions were objectively evaluated on a block scale based on the four dimensions of social, economic, physical, and institutional for modeling and evaluating the resilience of District 1.

\section{Study area}

The study area was District 1of Tehran which is located in the northeast of Tehran. This district with an area of about 210 square kilometers is located in the southern slopes of the Alborz Mountains. According to the 2016 census, this district has a population of 487508 people, including 238693 men and 248815 women. This district has a rural texture in terms of urban design. District 1 of Tehran runs a substantial risk of hazards due to its geographical location and is one of the most sensitive areas of Tehran.

Due to the high population density and concentration of administrative and economic centers in this district, there is a high probability of financial and human losses at the event of disasters. The absence of research targeted at preparing the resilience map of Tehran District 1 highlights the importance and necessity of modeling. Figure 1 displays the general situation of District 1 of Tehran.

\section{Districts of Tehran}

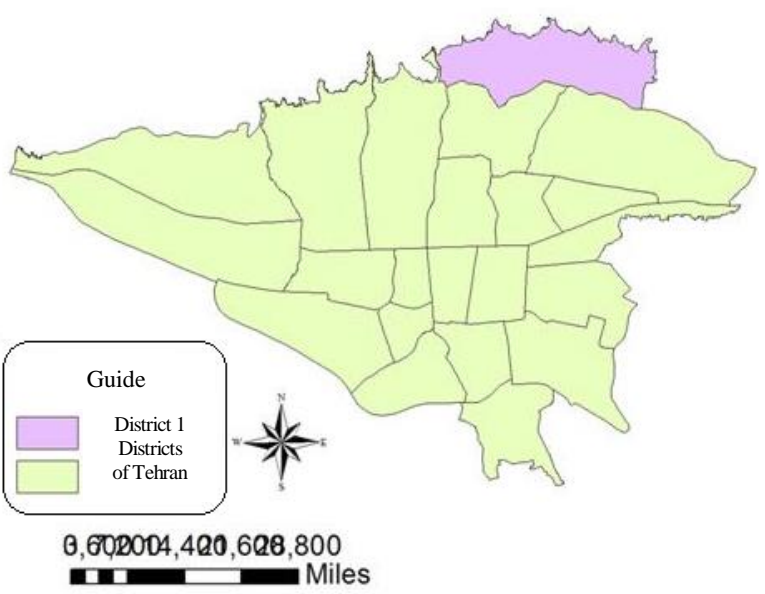

Figure 1. General situation of District 1 of Tehran 


\section{Methods}

The current research was conducted based on a descriptive-analytical method. Firstly, the indicators of physical and social resilience were extracted and identified using library and documentary studies, such as previous research studies and the use of expert opinions. Information about physical and social dimensions was extracted in the form of 14 components.

Physical dimension included distance from medical and relief centers, distance from hazardous centers and facilities, distance from main roads, distance from faults, street width, slope, land use, area, type of materials, number of floors, and population density. On the other hand, the social dimension entailed the age structure of the population, sex structure of the population, and educational level. The data collection method was library study and document analysis. Once the indicators were identified, binary maps of all indicators were prepared as resilient and nonresilient.

The indicators used in the present research are illustrated in Table 1. In this study, the Fuzzy

Table 1. Definition of resilience indicators used in the research

\begin{tabular}{|c|c|c|}
\hline Dimensions & Criteria & Definition \\
\hline \multirow{10}{*}{ Physical } & $\begin{array}{l}\text { Distance from } \\
\text { medical and relief } \\
\text { centers }\end{array}$ & $\begin{array}{l}\text { Relief centers in this study include fire stations, the Red Crescent, and } \\
\text { hospitals. The shorter the distance from these centers, the greater the } \\
\text { resilience. }\end{array}$ \\
\hline & $\begin{array}{l}\text { Distance from } \\
\text { hazardous centers } \\
\text { and facilities }\end{array}$ & $\begin{array}{l}\text { Installations that are associated with hazardous materials, such as gas } \\
\text { stations, transmission towers, gas, and water. The shorter the distance from } \\
\text { these centers and facilities, the lower the resilience. }\end{array}$ \\
\hline & $\begin{array}{l}\text { Distance from the } \\
\text { road and main routes }\end{array}$ & $\begin{array}{l}\text { In times of crisis, the short distance from the main roads and highways } \\
\text { provides paves the way for rescue resulting in more resilience. }\end{array}$ \\
\hline & $\begin{array}{l}\text { Distance from the } \\
\text { fault }\end{array}$ & $\begin{array}{l}\text { Due to the seismic strength of the faults, the greater the distance from the } \\
\text { fault, the more resilient the community. }\end{array}$ \\
\hline & $\begin{array}{l}\text { Street width } \\
\text { Slope }\end{array}$ & $\begin{array}{l}\text { In times of crisis, the wider passages allow for the easier provision of relief. } \\
\text { Buildings located on land with steep slopes are more vulnerable. }\end{array}$ \\
\hline & Land use & $\begin{array}{l}\text { This indicator is important in assessing the resilience of the study area due to } \\
\text { the possibility of proximity between two dangerous and safe uses. }\end{array}$ \\
\hline & Area & $\begin{array}{l}\text { The larger the building, the higher the level of open space, and as a result, relief } \\
\text { in the event of an accident is facilitated, and the resilience is increased. }\end{array}$ \\
\hline & Type of materials & $\begin{array}{l}\text { The quality of the building is directly related to the type of materials. } \\
\text { Therefore, if the types of building materials are better, vulnerability and } \\
\text { resilience will be more. }\end{array}$ \\
\hline & Number of floors & $\begin{array}{l}\text { Due to the high volume of debris and high population in buildings with } \\
\text { numerous floors, they have less resilience in the event of a crisis. }\end{array}$ \\
\hline & Population density & $\begin{array}{l}\text { Population density is the ratio of population to the area. This indicator is } \\
\text { directly related to reflection. }\end{array}$ \\
\hline \multirow{3}{*}{ Social } & $\begin{array}{l}\text { Age structure of the } \\
\text { population }\end{array}$ & $\begin{array}{l}\text { It means vulnerable age groups, which can be calculated through the percentage } \\
\text { of people over } 65 \text { years and children under } 6 \text { years of age in relation to the total } \\
\text { population of the region. The lower the ratio, the higher the latency. }\end{array}$ \\
\hline & $\begin{array}{l}\text { Sex structure of the } \\
\text { population }\end{array}$ & $\begin{array}{l}\text { Women are more vulnerable in times of crisis, and this indicator can be } \\
\text { calculated as the percentage of the total number of men compared to the total } \\
\text { number of women. This indicator is directly related to resilience. }\end{array}$ \\
\hline & $\begin{array}{l}\text { Educational level in } \\
\text { the region }\end{array}$ & $\begin{array}{c}\text { Educated people are less harmed in times of crisis due to their knowledge } \\
\text { and awareness. This indicator is calculated from the percentage of educated } \\
\text { people, compared to the population over } 6 \text { years old. The higher this ratio, } \\
\text { the higher the resilience. }\end{array}$ \\
\hline
\end{tabular}




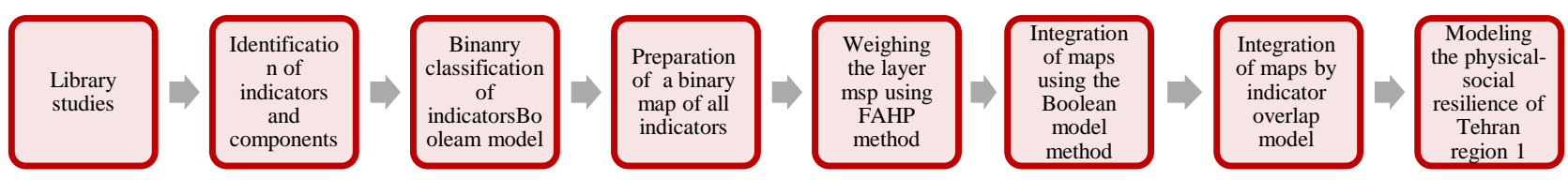

Figure 2. Flowchart of research stages

Analytic Hierarchy Process (FAHP) was used to weight the information layers, and the Boolean logic model and the indicator overlap model were utilized to combine the indicators. Figure 2 shows the general flowchart of the research process which is described below.

\section{A) Boolean logic model}

In this model, weighting the indicators in each information layer is based on logic 0 and 1 . In other words, every indicator on the map is either resilient or non-resilient, and there is no middle ground. In the final map, each pixel is identified as either resilient or non-resilient. In this model, operators such as AND, OR, NOT, and XOR are used to check whether a specific condition is True or False.

The result of the logical AND operator on several maps is equivalent to the sharing of those maps. The OR logic operation on two maps can be concluded by sharing (18). The current research used the logical AND which extracts based on the theory of subscriptions. In the same way, a corresponding map is prepared for all indicators using Boolean operators.

\section{B) Fuzzy hierarchical analysis process}

In the AHP method, the concept of being fuzzy is used indirectly without the use of fuzzy sets. In this method, fuzzy numbers are used to express the preference of the elements. The FAHP method has been developed to respond to uncertainties in decision-making. Therefore, in this research, FAHP was used to evaluate the information layers. This model was first proposed in 1983 by two Dutch researchers, Larhon and Perdircz.

The Larhon and Pedricz method suffers from some weaknesses that have been addressed in the
Buckley method which uses trapezoidal fuzzy numbers. In 1996, Chang introduced a new method called the Development Analysis Method which uses triangular fuzzy numbers (19-21). In Chang method, triangular fuzzy numbers are defined for pairwise comparisons after forming a decision hierarchy. A triangular fuzzy number is defined using an ordered set $(1, \mathrm{~m}, \mathrm{u})$ (Table 2).

The next step is to form a pairwise comparison matrix. The third step is the calculation of the value of $s_{\mathrm{k}}$ relative to the criterion $\mathrm{k}$ with respect to Equation 1.

$s_{k}=\sum_{j=1}^{n} M_{k j} *\left[\sum_{i=1}^{m} \sum_{j=1}^{n} M_{i j}\right]^{-1}$

Each of the obtained fuzzy numbers represents the relative weight of the criteria relative to each other. The next step is the calculation of the magnitude of the $s_{\mathrm{ks}}$ relative to each other. In general, if M1 and M2 are two triangular fuzzy numbers, the magnitude of $\mathrm{M} 2$ over M1 is defined using Equation 2.

$$
\left\{\begin{array}{c}
V\left(M_{1} \geq M_{2}\right)=1 \ldots \ldots \ldots \ldots \ldots \ldots \ldots \ldots \ldots \ldots \\
V\left(M_{1} \geq M_{2}\right)=\operatorname{hgt}\left(M_{1} \cap M_{2}\right) \\
\text { other } \quad \operatorname{hgt}\left(M_{1} \cap M_{2}\right)=\frac{u_{1}-l_{2}}{\left(u_{1-l} l_{2}\right)+\left(m_{2-} m_{1}\right)}
\end{array}\right.
$$

The weight of the indicators in the pairwise comparison matrix can be defined as follows (Equation 3), and the weight vector is obtained from Equation 4.

$$
\begin{gathered}
\left(W^{\prime}\left(X_{i}\right)=\min \left\{V\left(s_{i} \geq s_{k}\right)\right\} \ldots \ldots k=1,2, . . n, k \neq i\right. \\
w^{\prime}=\left[w^{\prime}\left(X_{1}\right), w^{\prime}\left(X_{2}\right), \ldots \ldots, w^{\prime}\left(X_{n}\right)\right]^{t}
\end{gathered}
$$

In the last stage, the normalized weight given

Table 2. Fuzzy spectrum and corresponding verbal expressions

\begin{tabular}{|ccc|}
\hline verbal expression & Fuzzy numbers & Inverse fuzzy numbers \\
\hline Equal & $1,1,1$ & $1,1,1$ \\
Important & $5,3,1$ & $1,1.3,1.5$ \\
More important & $7,5,3$ & $1.3,1.5,1.7$ \\
Very important & $9,7,5$ & $1.5,1.7,1.9$ \\
Quite important & $11,9,7$ & $1.7,1.9,1.11$ \\
\hline
\end{tabular}


for each indicator is obtained from Equation 5 $(22,23)$.

$w^{\prime}=\frac{w_{i}^{\prime}}{\sum w}$

The current study made use of fuzzy development analysis since it is easier to calculate compared to other FAHP methods.

\section{C) Indicator overlap model}

In this model, in addition to weighting the information layers, weigh is given to units in each information layer. The indicator overlap model can be performed in two ways. The first method is to weight binary maps. In this method, each map is only multiplied by its weight factor to be combined with other maps, and the maps obtained from the Boolean model are given a weight based on their importance. The second method is the multiclass maps. In this model, apart from weighting the input maps, each class and spatial unit is assigned a weight based on their importance (24).

Different methods for weighting the indicators include logistic regression, ratio estimation, hierarchical analysis process, and weight of evidence. In this research, the first method was used for weighting the indicators, and binary maps were utilized as input. Thereafter, the weight of each indicator was obtained using expert opinions and the FAHP weighting method and multiplied by the relevant layer. Finally, all the layers were summed up, the values of the final map were converted to values from $0-10$, and priority was given to the resilience of different areas.

\section{Findings}

In order to develop a conceptual physicalsocial resilience model of District 1 of Tehran, after the identification of effective factors in this area, indicators were binary classified at the outset (Table 3). Physical resilience is one of the dimensions involved in the assessment and calculation of resilience. It allows us to assess the physical and geographical characteristics of the region at the event of hazards.

To this end, to prepare the resilience map of this dimension, such indicators as the distance from medical and relief centers, distance from hazardous centers and facilities, distance from main roads, distance from faults, street width, slope, land use, area, type of materials, and the number of floors were investigated. Social resilience will increase the power of planning and prediction for the future. In this connection, such indicators as population density, the age structure of the population, sex structure of the population, and the educational level in the district were considered in the social dimension.

As illustrated in Table 1 which is the result of previous research and expert opinions, the map of identified indicators as binary- that is to say, resilient or non-resilient, and the input information layer was determined for the next step. The classified information layer of each indicator is presented in Figure 3.

The final resilience map was obtained by combining classified information layers (indicator binary maps). The map resulting from integration with the Boolean method is depicted in Figure 4, and the one resulted from integration with the indicator overlap method is displayed in Figure 5.

Before the combination of layers with the indicator overlap method, pairwise comparisons of the layers were performed by experts using the fuzzy hierarchical analysis process, and the final weight of the layers was obtained (Table 4). The Boolean method is rigorous and may not produce any output after the combination of layers or the output may be the results of a small area. This model merely presents resilient and non-resilient areas and is not able to classify the resilience according to the first, second,... priority. Accordingly, the slightly unsuitable regions do not stand a chance of being selected.

In this method, the study areas are either $100 \%$ resilient or $100 \%$ non-resilient. The inability of this method to classify the resilience of the region was the reason for using the indicator overlap model. In the indicator overlap method, nonresilient regions were assigned to six classes of low to high non-resilience.

Based on the preparation and analysis of the physical-social resilience map in District 1 of Tehran, the following results were obtained:

According to the result of the Boolean model map, more than half of the total district with an area of 15919631 square meters will be nonresilient, and an area of about 12731230 square meters will be resilient. Nonetheless, based on the result of the indicator overlap method, about 14297814 square meters of the district is nonresilient, and 12120886 square meters is resilient. 
It was found that $7.68 \%$ of the total district with an area of about 931896 square meters (class 1,2) have low resilience, $24.71 \%$ of the district with an area of 2995380 square meters (class 4 and 3) have average resilience, and $67.61 \%$ of the district with an area of about 8193610 square meters (classes 6 and 5) has a high degree of resilience. According to the results of the current

Table 3. Indicator, sub-indicator, and their classification

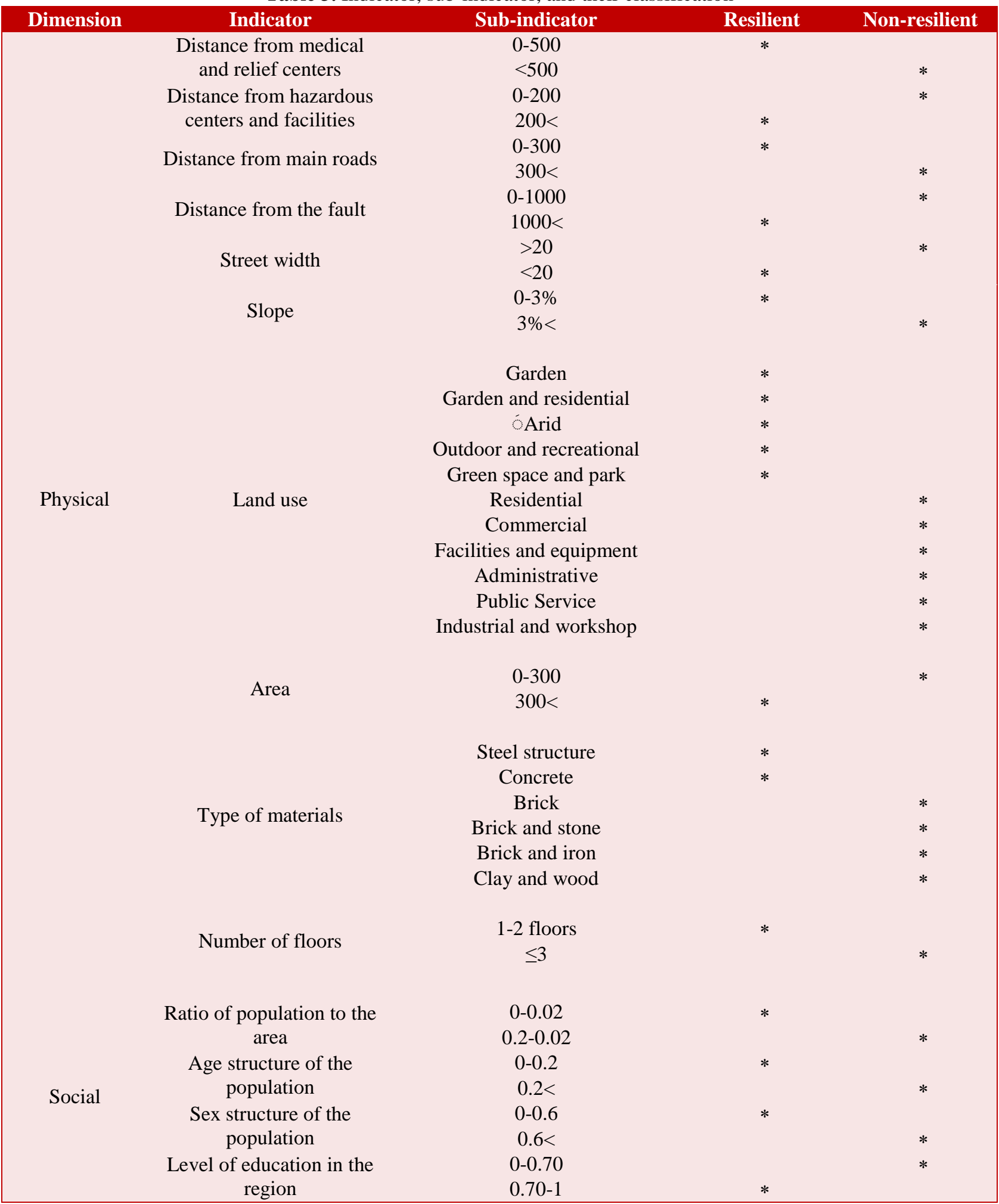



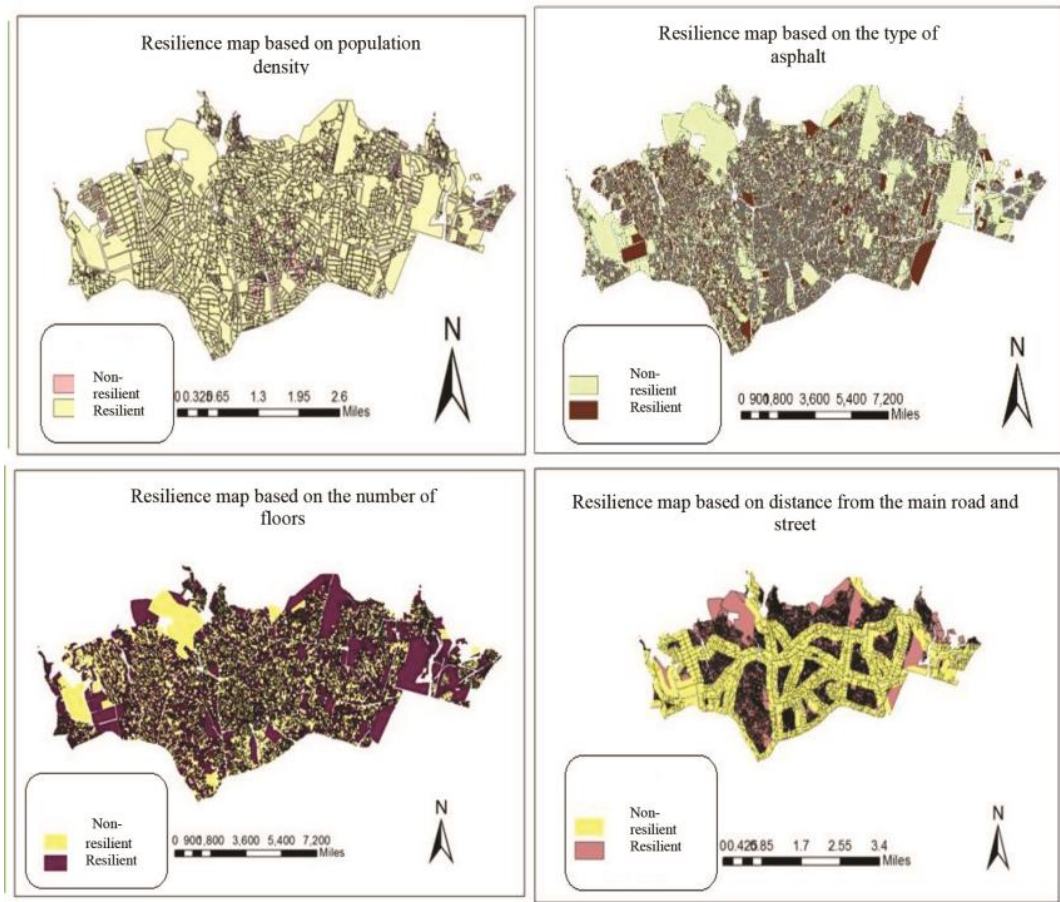

Resilience map based on distance from the main road and

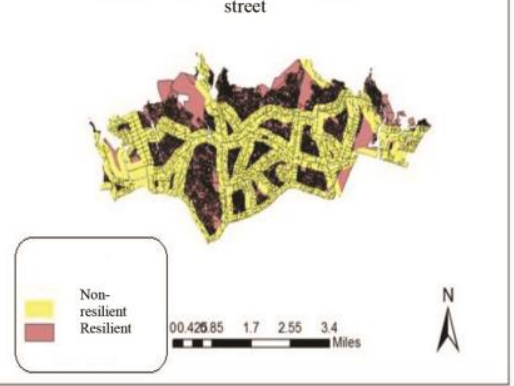

Non-resulient

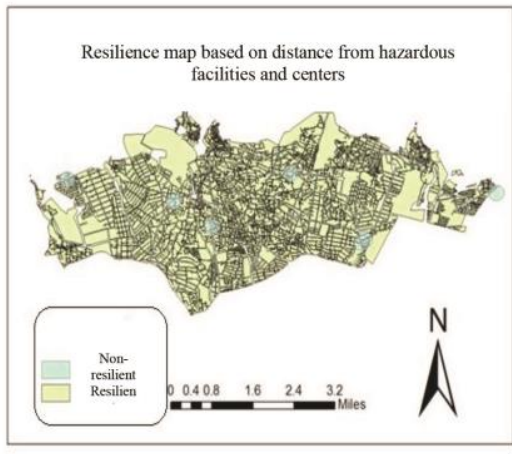

Resilience map based on distance from medical and service
centers
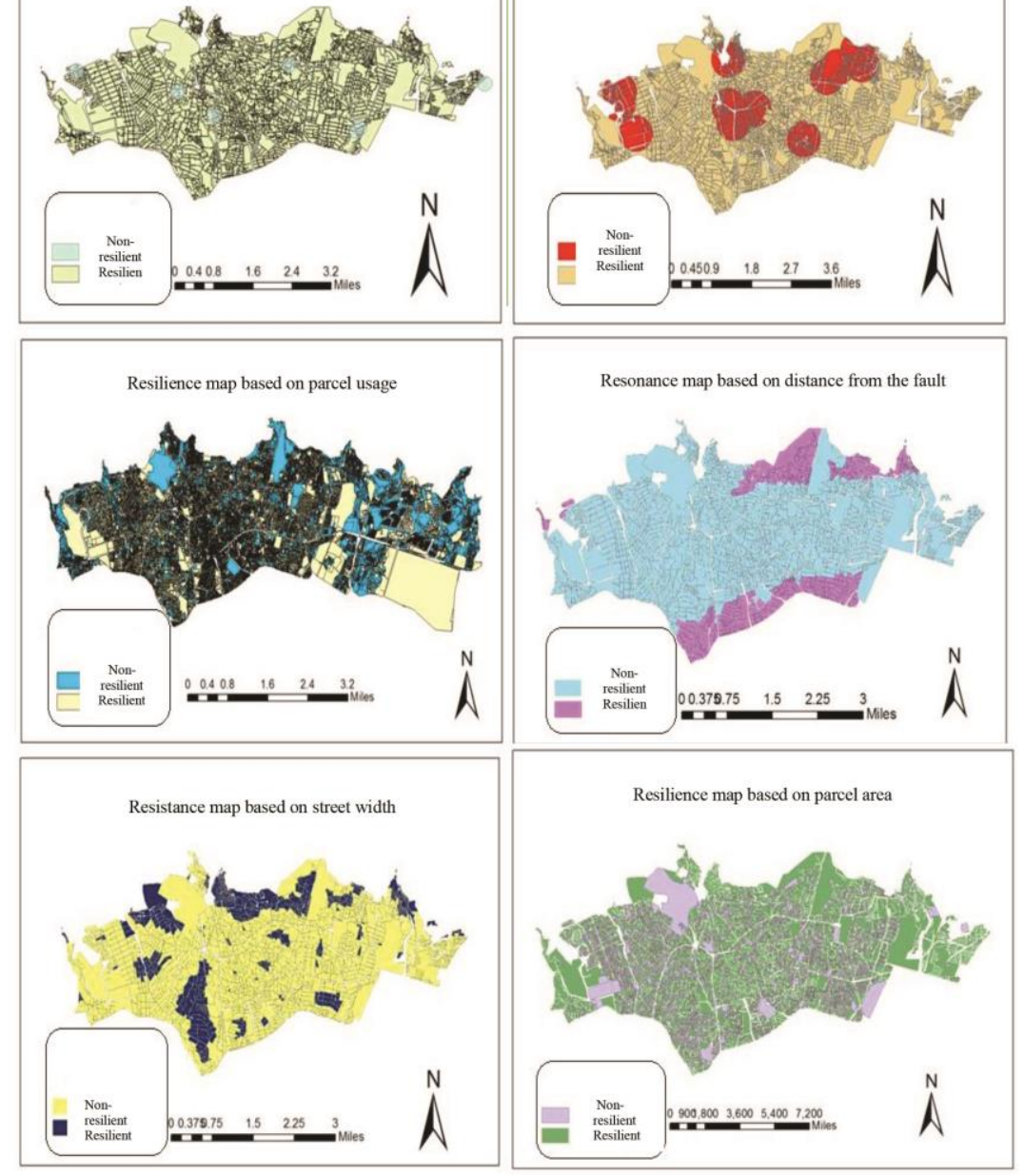

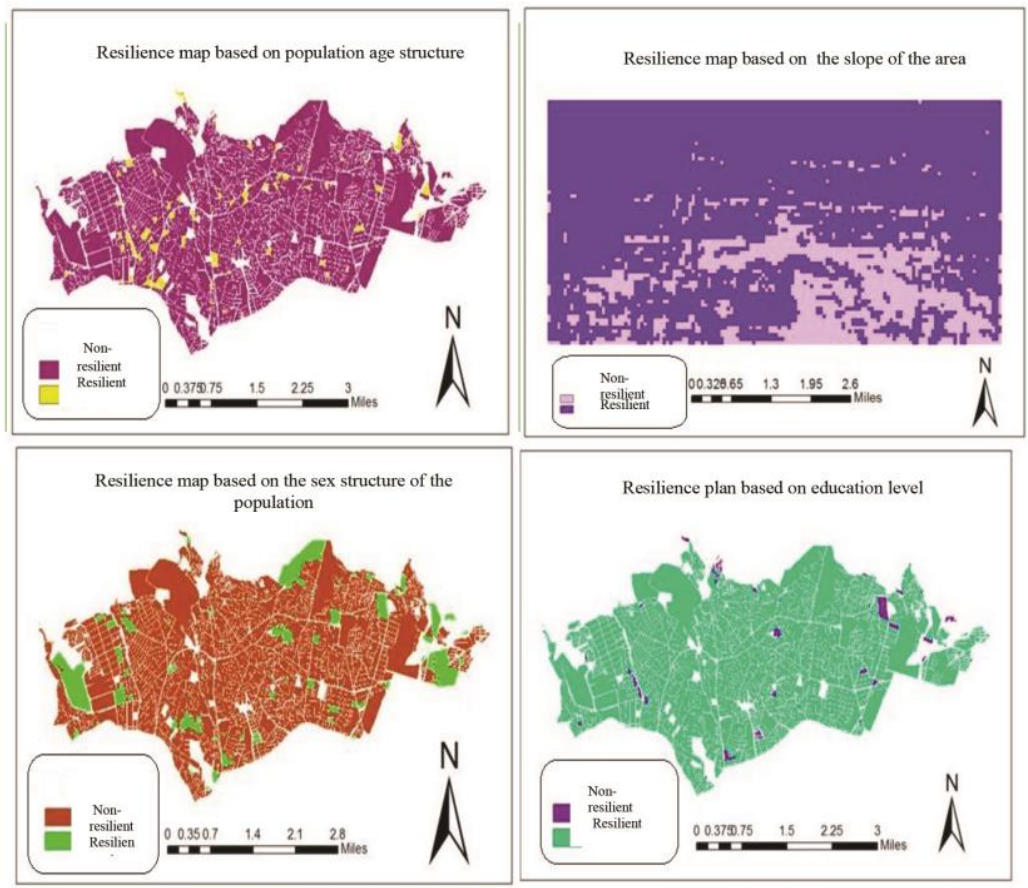

Figure 3. Binary map of the studies parameters

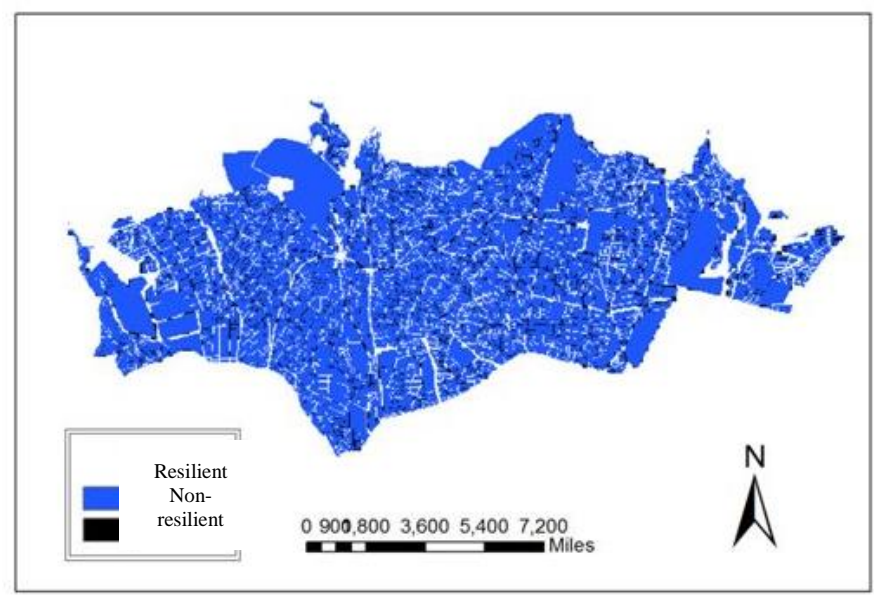

Figure 4. Resilience map of District 1 of Tehran using Boolean method

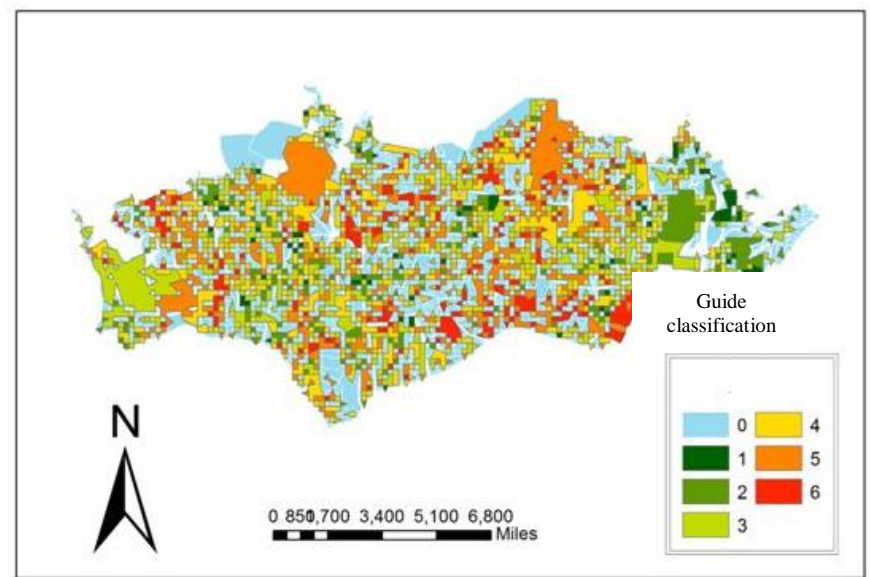

Figure 5. Resilience map of District 1 of Tehran using the indicator overlap method 
Table 4. Final weight of indicators

\begin{tabular}{|c|c|c|c|c|}
\hline Dimension & Indicator & Weight of dimension & $\begin{array}{l}\text { Weight of } \\
\text { indicator }\end{array}$ & $\begin{array}{c}\text { Final } \\
\text { weight }\end{array}$ \\
\hline \multirow{10}{*}{ Physical } & Distance from the fault & \multirow{10}{*}{0.7} & 0.047 & 0.033 \\
\hline & Distance from main roads & & 0.097 & 0.068 \\
\hline & Distance from medical and relief centers & & 0.101 & 0.071 \\
\hline & Distance from hazardous centers and facilities & & 0.132 & 0.092 \\
\hline & Slope & & 0.06 & 0.042 \\
\hline & Area & & 0.108 & 0.076 \\
\hline & Type of materials & & 0.149 & 0.104 \\
\hline & Number of floors & & 0.133 & 0.093 \\
\hline & Street width & & 0.092 & 0.064 \\
\hline & Land uses & & 0.081 & 0.057 \\
\hline \multirow{4}{*}{ Social } & Ration of the population to area & \multirow{4}{*}{0.3} & 0.269 & 0.081 \\
\hline & Age structure of the population & & 0.264 & 0.080 \\
\hline & Sex structure of the population & & 0.25 & 0.075 \\
\hline & Education level in the region & & 0.217 & 0.065 \\
\hline
\end{tabular}

research, the southern part of District 1 of Tehran has low resilience. This region and all other nonresilient areas can be identified in Figure 5. Other results indicated that District 1of Tehran is in a favorable situation in terms of social resilience and population characteristics. Nevertheless, in terms of physical dimensions, it is in an unfavorable situation due to proximity to the fault, the high slope of the area, and high-rise buildings with low-strength materials. Therefore, due to the importance of the physical dimension indicators, the relevant authorities should take the necessary measures to expand community resilience.

\section{Discussion and Conclusion}

Crisis management has not played an effective role regarding natural hazards, and we have always witnessed huge financial and human losses in these circumstances. Today, governments are pursuing a resilience approach to reduce the effects of natural hazards. The present study aimed to prepare a physical-social resilience map of District 1 of Tehran using the Boolean method, indicator overlap method, and fuzzy hierarchical process.

The resilience map of the study area demonstrated that the southern areas of district 1 of Tehran are more non-resilient, and Darband area and its surroundings are more likely to be damaged in the event of hazards.

In general, areas 6, 5, 2, and 3 are less resilient, respectively. The regions with greater distances from hazardous centers and facilities, materials with stronger strength, and fewer floors are more resilient.

The results of the present study revealed that more than half of the study area is non-resilient. In a similar vein, the findings of other studies have shown n0n-resilience in other cities of Iran. As documented in related studies, numerous indicators, such as geomorphological and geological characteristics and the age of buildings are of great help in identifying the resilience of the region. However, due to the unavailability of this information, the impact of these factors on decision-making was not considered.

On a final note, according to the results of the present study, the relevant authorities should take the necessary measures and controls at the earliest opportunity. To this end, to improve safety, reduce vulnerability, and increase community resilience, the following strategies can be implemented: development of cities in suitable places, the construction of temporary housing in more resilient centers, using durable structures, observing the appropriate distance from faults and hazardous centers and facilities, widening streets, lanes, ways, and passages, alternative access routes, and public awareness of vulnerabilities.

\section{Acknowledgments}

The authors' deepest appreciation goes to all those who contributed to this research project.

\section{Conflict of Interests}

The authors declare that they have no conflict of interest regarding the publication of the current study. 


\section{References}

1. Pourahmad A, Lootfi S, Faraji A, Azimi A. Investigating the dimensions of prevention of earthquake crisis (a case study of Babol). Urnan Reg Stud Res 2009; 1(1): 1-24. [In Persian].

2. O'brien K, Sygna L, Haugen JE. Vulnerable or resilient? A multi-scale assessment of climate impacts and vulnerability in Norway. Climatic Change 2004; 64(1-2): 193-225.

3. Normandin JM, Therrien MC, Tanguay GA. City strength in times of turbulence: strategic resilience indicators. Proc. of the Joint Conference on City Futures, Madrid; 2009.

4. Rezaei MR, Rafieian M, Hosseini SM. Measurement and evaluation of physical resilience of urban communities against earthquake (case study: Tehran neighborhoods). Hum Geography Res Quart 2015; 47(4): 609-23. [In Persian].

5. Forgette R, Boening VM. Measuring and modeling community resilience: SERP and DyME. Mississippi: University of Mississippi; 2011.

6. International Strategy for Disaster Reduction. Hyogo framework for action 2005-2015: Building the resilience of nations and communities to disasters. Extract from the Final Report of the World Conference on Disaster Reduction (A/CONF. 206/6), New York, USA; 2005.

7. Badri SA, Ramezanzadeh Lasboei M, Asgary A, Ghadirimasom M, Salmani M. The role of local management in improving resilience to natural disasters with emphasis on floods. J Emerg Manag 2013; 2(1): 39-50. [In Persian].

8. Zanganeh SS, Ziari K, Pourakrami M. Evaluation and analysis of 12 district of Tehran physical resilience against earthquakes by using fanp and vikor. Geography 2017; 15(52): 81-101. [In Persian].

9. Zali N, Sohrabi M. An analysis of the influential factors in regional resiliency using TRIZ technique; a case sudy in Hamedan province. J Regional Plan 2018; 8(29): 41-52. [In Persian].

10. Nayeri M, Shieh E, Rezaei M, Saeidi Rezvani N. Land-use planning in the face of earthquakes in worn-out texture (case study: Abdulabad, Tehran, Iran). Hum Geography Res Quart 2019; 51(2): 26990. [In Persian].

11. Farzad Behtash MR, Keynejhad MA, Pirbabaei MT, Asgary A. Evaluation and analysis of dimensions and components of Tabriz metropolis resiliency. Memari-Va-Shahrsazi 2013; 18(3): 3342. [In Persian].

12. Rafiyan M, Rezaei MR, Asgari A, Parhizkar A, Shayan S. Conceptual explanation of resilience and its indexing in community-based disaster management (CBDM). J Spatial Plan 2011; 15(4): 19-42. [In Persian].

13. Bahrami S, Sarvar R, Asadian F. The evaluation and analysis of institutional and physical resilience of urban neighborhoods of Sanandaj. Geographical J Territory 2018; 15(59): 15-38. [In Persian].

14. Heidari R, Gholami Y, Salimi Z. Resilience assessment of physical urban areas against earthquake: the case of old neighborhoods in Bushehr. Geography Environ Hazards 2018; 6(24): 63-80. [In Persian].

15. Maleki S, Amanpour S, Safaeepour M, Pormosavi $\mathrm{SN}$, Mavedat E. Evaluation of urban physical resilience spectrum the against earthquake using the model planning (a case study of Ilam). J Phys Dev Plan 2017; 2(1): 9-20. [In Persian].

16. Zanganeh SS, Ziari K, Pourakrami M. Evaluation and analysis of 12 district of Tehran physical resilience against earthquakes by using fanp and vikor. Geography 2017; 15(52): 81-101. [In Persian].

17. Rousta M, Ebrahimazadeh I, Istgaldi M. Assessment of urban social resilience (case study: city of Zahedan). Res Urban Plan 2018; 9(32): 114. [In Persian].

18. Delake H, Samare MB, Shahivandi A. Evaluation of social resilience in urban areas of Isfahan. J Sociol Soc Institut 2017; 4(9): 227-52. [In Persian].

19. Salehi E, Rafii Y, Farzad BM, Aghababaei MT. Urban flood hazard zonation using GIS and fuzzyAHP analysis (case study: Tehran city). J Inviron Stud 2013; 39(3): 40-2. [In Persian].

20. Arman Mohammad H, Mojdeei S, Hossein Beigi AR. An extension of approximate methods for determining the relative weights and ultimate weights of alternatives in Fuzzy AHP. 8th International Management Conference, Tehran, Iran; 2009. [In Persian].

21. Mikhailov L, Tsvetinov P. Evaluation of services using a fuzzy analytic hierarchy process. Appl Soft Comp 2004; 5(1): 23-33.

22. Shirmard H, Bahroudi A, Adeli A. Fuzzy AHP method in GIS for determining the optimal drilling points in the Naisian Porphyry Copper mine. Sci Res Quart Geographical Data 2015; 24(93): 91-100. [In Persian].

23. Ghassemi SA, Danesh S. Application of fuzzy analytical hierarchy process in determining the optimum alternative of brackish water desalination. J Water Soil 2012; 26(4): 999-1009. [In Persian].

24. Khaje Shahkoohi AR, Davoodi M, Hesam M. Spatial modeling and multi-criteria decision making. Golestan: Golestan University; 2014. [In Persian]. 